\title{
KANT, REPUBLICANISMO Y SOCIEDAD CIVIL
}

\author{
Kant, Republicanism and Civil Society
}

Alessandro Caviglia*

\begin{abstract}
RESUMEN
El presente artículo presenta de qué manera el republicanismo desde la sociedad civil permite tener una crítica de los fenómenos presentes en las sociedades contemporáneas, especialmente las formas de despotismo que se basan en dogmatismos y fundamentalismos. Para ese fin, comienza presentando la manera en la que los pensamientos de Hume y Rousseau son aprovechados por Kant para articular una concepción republicana. Seguidamente, pasa a ver el modo en que dicha concepción permite hacer crítica de la sociedad civil contemporánea.
\end{abstract}

\section{Palabras clave:}

Kant, republicanismo, sociedad civil, Rousseau, Hume, moral.

\begin{abstract}
This paper presents how republicanism from within civil society makes possible a critique of the phenomena that are present in contemporary societies, especially some forms of despotism based on dogmatisms and fundamentalisms. To that end, it begins by presenting the way in which Hume and Rousseau's thoughts are used by Kant to articulate a republican conception. Next, it goes on to see how this conception allows for a criticism of contemporary civil society.
\end{abstract}

\section{Keywords:}

Kant, republicanism, civil society, Rousseau, Hume, moral

* Pontificia Universidad Católica del Perú: ascaviglia@yahoo.com 


\section{INTRODUCCIÓN}

Sin lugar a duda, la filosofía política y social de Kant se encuentra asociada a la tradición republicana que desde el pensamiento articulado por los pensadores de la República Romana y pasando por Rousseau llega al filósofo alemán. Ahora bien, el republicanismo kantiano ha sido tradicionalmente entendido como una concepción política que se articula desde el Estado y que desde allí irradia su potencial democrático hacia la sociedad (Brandt, 1997, Nissen, 2001). Sin embargo, hay razones fuertes para pensar la posibilidad de un republicanismo kantiano que parte desde la sociedad civil, aunque el filósofo de la Ilustración no desarrollara una concepción de esta. Así, si uno asume la perspectiva de Kant que se encuentra no sólo en el texto La paz perpetua, sino que revisa también El conflicto de las facultades y Respuesta a la pregunta ¿qué es la Ilustración? puede tener una compresión más amplia del republicanismo y entender de qué manera el filósofo alemán apuesta por el fortalecimiento de las relaciones republicanas en el seno de la sociedad civil.

La idea de republicanismo a partir de la sociedad civil permite percibir con claridad que para que una sociedad se consolide como una república democrática no basta con que el Estado adquiera una estructura determinada, sino que, si la sociedad no se democratiza y no se establecen relaciones republicanas de no dominación entre los ciudadanos, el proyecto republicano fracasa inevitablemente. Además, la perspectiva del filósofo de la Ilustración permite analizar los fenómenos en los que, a pesar de que no se ha consolidado un
Estado republicano, es posible encontrar una sociedad civil que ha articulado procesos de democratización propios de una sociedad civil republicana.

En nuestro mundo contemporáneo son palpables ambos fenómenos. De un lado, asistimos a los ascensos de los populismos, tanto de izquierda como de derecha, así como a los fundamentalismos religiosos, laicos y económicos, proyectos todos que se encuentran hechos con la tela del dogmatismo y que vehiculan relaciones basadas en diferentes formas de dominación, tanto a nivel político, como social, económico o en el ámbito de las formas de vidas más domésticas. De otra parte, podemos ver procesos de democratización social a pesar de la precariedad de las instituciones estatales o en el seno de Estados despóticos o autoritarios.

El pensamiento de Kant, que ha bebido del escepticismo de David Hume ante toda metafísica dogmática como de la crítica a toda forma de dominación a través del estudio de las obras de JeanJaques Rousseau, sirve como punto de vista crítico a esas formas de dominación que campean en el mundo actual. En lo que sigue presentaré de qué manera el republicanismo kantiano exige la democratización de la sociedad civil como piedra de toque para la instauración de relaciones republicanas tanto en el Estado como en la sociedad. Para ello presentaré los aportes que recoge Kant en David Hume y Jean-Jacques Rousseau (1) para, seguidamente mostrar la forma en la que Kant utiliza dichos aportes para hacer crítica de las relaciones políticas y sociales (2). Finalmente, volcaremos la crítica kantiana sobre los fenómenos políticos y sociales más perniciosos del mundo contemporáneo, especialmente el populismo (3). 


\section{REPUBLICANISMO, HUME Y ROUSSEAU}

Tanto David Hume como Jean-Jacques Rousseau han sido importantes para la elaboración de la crítica de las relaciones políticas y sociales hecha por Kant. Cargado de las armas del escepticismo, Hume arremete contra las posiciones dogmáticas en la metafísica. Al mismo tiempo, utilizando las herramientas republicanas que provienen de Rousseau, el filósofo alemán lleva adelante una crítica a las relaciones despóticas de dominación.

\subsection{EL ESCEPTICISMO ANTIDOGMÁTICO DE HUME}

Como lo advierten tanto Hume como Kant, el ataque a la metafísica dogmática tiene consecuencias políticas y sociales directas. El escepticismo de Hume lo emprende directamente contra el dogmatismo religioso y sus implicancias para las relaciones sociales y políticas. El argumento de Hume en defensa del escepticismo se presenta en las Investigaciones sobre el conocimiento humano. En dicha obra el filósofo escocés señala que no se puede afirmar que se tiene conocimientos de las esencias de las cosas o de objetos metafísicos. Así, por ejemplo, de la observación de las cualidades sensibles del pan (el olor, el color y la textura) no puedo extraer la afirmación de que al ingerirlo nutrirá. Las cualidades nutritivas que solemos atribuirle son como ciertos "poderes ocultos" cuya existencia no se puede probar. Lo mismo sucede con las supuestas propiedades ocultas del fuego y del agua que sustenta la suposición de que si pongo el agua sobre el fuego esta hervirá. La conclusión que Hume extrae va directamente contra el principio de causalidad que sustenta la física de su tiempo, a saber, la física de Newton.
El principio de causalidad supone que existe una conexión necesaria entre un evento X y un evento Y, como, por ejemplo, "ingiero pan" y por lo tanto "éste me nutrirá", o "dejo en el aire una piedra" y, en consecuencia "ésta caerá". Dicha conexión se atribuye a la existencia de un principio denominado "principio de causalidad". Pero, como señala Hume, ese principio, presentado de esa manera, cuenta con una serie de presupuestos que necesitan explicación. Especialmente suponen determinados conocimientos metafísicos que no tenemos a disposición, como son ciertas propiedades ocultas en las cosas que no se pueden captar por medio de los sentidos. De esta manera, yo no puedo esperar que todas las veces que se dé el evento $X$ se siga el evento Y. Podría, muy bien suceder que deje la piedra en el aire y comience a flotar, o que coloque el agua sobre el fuego y se convierta en cubos de hielo. Lo que consigue Hume con esta operación es convertir al principio de causalidad en un producto de la mera costumbre. Afirmamos que después de $\mathrm{X}$ se dará Y porque estamos acostumbrados a que así ha venido sucediendo hasta el momento, pero en realidad no existe ningún fundamento para esa creencia (Hume, 2003, 58-59).

Esto es así porque lo que Hume está cuestionando son supuestos conocimientos metafísicos que se han instalado de manera dogmática. El escepticismo que el filósofo escocés abraza cuestiona abiertamente todo dogmatismo, a la par de toda posición metafísica. El dogmatismo se encuentra articulado por un conjunto de creencias coherentes, compacto y cerrado, que no permite alguna crítica y que no es capaz de dar razón sobre sus fundamentos últimos. A su vez, la metafísica, tal como Hume la entiende, es el campo en el que 
se presentan las posiciones dogmáticas (Hume, 2003, 194-195). Kant beberá de este escepticismo, comprometiéndose con el antidogmatismo. Pero no asumirá el rechazo a toda forma de metafísica, más bien asumirá una metafísica crítica. Tampoco rechazará el principio de causalidad como fundamento de las ciencias naturales, sino que lo defenderá, pero otorgándole un estatuto diferente al que Newton y Hume le dieron. Así que, en vez de señalar que el principio de causalidad se presenta como un hecho en el mundo externo del sujeto, el filósofo alemán señalará que se trata de una categoría presente en la mente humana y que permite articular los fenómenos.

\subsection{EL REPUBLICANISMO EN ROUSSEAU}

El pensamiento de Rousseau resulta ser bastante asistemático y complejo, pero en su teoría política y social defiende con claridad una vertiente del republicanismo, que hunde sus raíces en las obras de los pensadores de la república romana. En obras como El contrato social, Las confesiones, o El Emilio, entre otras, defiende con claridad dichas posiciones republicanas. El republicanismo de Rousseau se asienta en dos ideas fundamentales. La primera es la de no estar dominado por otros, mientras que la segunda consiste en que la determinación de lo correcto y lo incorrecto se determina por medio del intercambio de razones.

De esta manera, el republicanismo de Rousseau se mueve a dos niveles. En el primero se centra en la idea de no estar dominado, lo que Philip Pettit denomina libertad como no dominación (Pettit, 1999, 95). Estar dominado implica encontrarse sometido a la voluntad arbitraria de cualquier otro. La relación de dominación paradigmática es la que establece el amo sobre el esclavo. El amo se encuentra en condiciones de tratar al esclavo como si fuese una cosa, eliminando por completo su voluntad. De esta manera, el amo tiene un poder efectivo o potencial sobre el esclavo. De esta forma, la relación de dominación es de carácter personal, en el sentido en que se ejerce entre personas, anula la voluntad de la persona dominada y la reduce a nivel de objeto. En sus obras, Rousseau realiza una constante crítica de las relaciones de dominación que se realizan a nivel interpersonal, social y político (Rousseau, 1998, 2008 y 2015). Uno de los puntos de su crítica a la sociedad en la que vivió fue el poder que tenía la iglesia sobre la política y las relaciones sociales. En el contexto en el que Rousseau desarrolló su pensamiento, que es el de la Francia pre-revolucionaria, la Iglesia Católica tenía un gran poder político y social, y establecía relaciones de jerarquía y dominación en la sociedad. Esto hizo que el filósofo de Ginebra buscase reemplazar toda religión revelada por una religión civil que sería la base para las relaciones republicanas entre los ciudadanos y el Estado (Rousseau, 1996, 155-165)

El segundo nivel se desarrolla en el intercambio de razones. Tal como lo señala Thomas Scanlon, un republicanismo inspirado en las ideas de Rousseau se centra en el intercambio de razones y considera a la persona como un centro de razones. (2003, 20-21) Es por eso por lo que la moral republicana de Rousseau es heterónoma, pero en un sentido muy específico. Es heterónoma en el sentido en el que no se trata de un sujeto aislado que determina lo correcto y lo incorrecto, sino que se trata de que ello se realiza entre las personas a través del intercambio de razones. Si bien este segundo nivel del republicanismo no aparece tematizado en la obra del filósofo helvético, se puede 
percibir con claridad a lo largo de su obra en la que se presentan situaciones y casos en los cuales los personajes se encuentran intercambiando razones o donde determinados personajes lamentan la ausencia de dicho ejercicio. Una obra paradigmática al respecto es Rousseau juez de Jean-Jacques (Rousseau, 2015).

\section{LA CRÍTICA KANTIANA A} LAS RELACIONES POLÍTICAS Y SOCIALES

La filosofía crítica de Kant bebe tanto de Hume como de Rousseau. De esta manera, articula la crítica al dogmatismo con el cuestionamiento a las relaciones de dominación. En otras palabras, Kant une aquello que Hume y Rousseau mantienen separado. Lo que encuentra el filósofo de Königsberg es que el elemento que hace posible la dominación no es tanto la fuerza física sino el poder de los discursos dogmáticos. De esta manera, la operación crítica consiste en cuestionar el dogmatismo a fin de abrir paso a un debilitamiento de las relaciones de dominación.

El problema que Kant encuentra en la metafísica (es decir, en la filosofía) es que se encuentra atrapada por posiciones dogmáticas y por cierta forma de escepticismo no crítico de sus propios presupuestos. La saturación de racionalidad que caracteriza a las posiciones dogmáticas no permite que se abra un debate entre ellas. Pero, al mismo tiempo, las mismas posiciones dogmáticas tienen consecuencias sociales y políticas que terminan generando dominación entre las personas. Así, si alguien se atribuye el conocimiento de la naturaleza humana entonces creerá que tiene el derecho a decirle a las personas cómo deben vivir sus vidas y de qué manera deben relacionarse con su propio cuerpo. De esta manera, el monarca absoluto organiza la vida de sus súbditos y los sacerdotes colocan prescripciones sobre la conducta privada de las personas. Todo ello, en virtud de un supuesto conocimiento metafísico que es de carácter dogmático.

La crítica de la razón que Kant desarrolla tiene como objetivo cuestionar las posiciones dogmáticas para abrir paso a la libertad y a la autonomía. Ello se realiza en la parte de la Crítica de la razón pura que se llama "dialéctica trascendental", especialmente en la sección dedicada a "las antinomias de la razón" (Kant, 2009, 422). Una antinomia es el enfrentamiento entre posiciones dogmáticas antagónicas. Cada posición, ya sea la tesis o la antítesis, es completamente cerrada y uno podría explicar a través de ella, la realidad en su conjunto de manera completa. Por ejemplo, la tercera antinomia (Kant, 2009, 441) versa sobre el determinismo y sobre la libertad. La tesis señala que todo lo que existe puede explicarse por medio de relaciones causales, de tal manera que la libertad no existe en el mundo, y si uno considera que es libre es porque es víctima de una ilusión. De esta manera, en el mundo nada actúa de manera espontánea y libre. Esta explicación es completamente coherente y consistente, y uno podría explicar la totalidad de la realidad de esta manera, pero sucede que frente a ella se erige la antítesis que sostiene la existencia de la espontaneidad y la libertad en el mundo. La antítesis que afirma la libertad tiene en sí la misma consistencia, coherencia y capacidad explicativa, de tal manera que parece ser difícil decantarse por alguna de estas posiciones.

¿Cuál es el problema que encierran estos enredos del pensamiento humano que Kant denomina antinomias? ¿Por 
qué las personas parecen encontrarse atrapadas en estas posiciones dogmáticas? Las posiciones dogmáticas examinadas por Kant y que constituyen los elementos de las cuatro antinomias de la razón (como es el caso de toda posición dogmática) tienen el siguiente problema: suponen que se tiene conocimiento sobre objetos que se encuentran más allá de la experiencia, como el alma, el mundo y Dios. Toda filosofía dogmática da por sentado que las mismas categorías que usa el entendimiento para articular los datos de la experiencia se pueden utilizar para conocer los objetos que se encontrarían más allá de la experiencia. Así, por ejemplo, si el principio de causalidad nos permite articular los datos sensibles y articular la experiencia, la filosofía dogmática sostiene que uno puede remontarse a las causas más remotas que trascienden toda experiencia posible y conocer el origen de la realidad o a Dios.

Kant es consciente de que la actividad y las ansias de conocimiento teórico que desborda la experiencia es inherente a la dinámica de la razón humana. Toda persona cultiva en su corazón y en su mente la aspiración de conocer cosas que van más allá de la experiencia. A eso denomina Kant "metafísica como disposición natural". Pero las personas deben tener mucho cuidado de esa tendencia, puesto que puede conducirlas a ser víctimas de relaciones de dominación. El poco cuidado por parte de los filósofos ha hecho que dicha tendencia a tener conocimientos teóricos de cosas que no se pueden conocer termine por producir la situación de que el pensamiento metafísico termine siendo capturado por posiciones dogmáticas. Esto terminó por hundir a la metafísica en una profunda crisis y como remedio de la misma Kant propone la crítica de la razón. ¿En qué consiste la crítica? En una maniobra que tiene dos pasos. El primer paso consiste en distinguir el área de la razón teórica de la de la razón práctica. El segundo paso consiste en reemplazar el estatuto de conocimiento teórico a aquellas pretensiones que tenemos sobre objetos que se encontrarían más allá de la experiencia y colocarlos en el campo de la razón práctica bajo el estatuto de postulados o ideas de la razón.

Kant explica con claridad que la razón es una sola, pero tiene dos usos diferentes. El primero es el uso teórico y está dirigido al conocimiento de objetos de la experiencia. El segundo, en cambio, es práctico y está dirigido a producir ideas regulativas. Las ideas regulativas son aquellas que permiten orientarnos en la práctica. Ahora bien, Kant establece una relación muy particular entre el término "práctico" y la libertad. De una parte, la libertad es una idea de la razón práctica. En este sentido, la libertad no es algo que se puede conocer, puesto que no es un objeto como la pantalla de una laptop o los dedos de la mano. Pero es algo que debemos suponer necesariamente si queremos darle sentido a fenómenos de la experiencia, como la imputación legal o atribuirles determinadas acciones y responsabilidad a los sujetos. De este modo, la libertad es un presupuesto práctico, no teórico. Pero, por otra parte, "práctico" es todo aquello que involucra la libertad, de manera que aquello que denominamos know how no es práctico, sino teórico, porque supone un conocimiento de las causas eficientes que se encuentran en el mundo de la experiencia. La libertad, en vez de involucrar un conocimiento del entendimiento supone una acción de la voluntad.

Tanto la metafísica dogmática como el escepticismo de Hume carecen de la distinción entre el campo teórico y 
práctico de la razón. Esta distinción es propia de la crítica. La actividad crítica consiste en limitar las pretensiones de conocimiento teórico y a la vez abrir el campo de la razón práctica. En esta jugada el término "razón" comienza a adquirir un nuevo significado. Ya no se opone a sensibilidad, sino que se opone al conocimiento teórico. Así, mientras que el entendimiento tiene explicaciones sobre los fenómenos del mundo, la razón es algo eminentemente práctico, se trata de razones para actuar. Mientras que las explicaciones son teóricas, las razones son prácticas, así, tener una razón no es tener un conocimiento, sino tener un "motivo" para actuar.

De esta forma, la "teoría" de la acción que se desprende de esta distinción supone que las razones para actuar no provienen de conocimiento teórico alguno en torno a las condiciones del mundo o las condiciones de los sujetos que actúan en el mundo. De esta manera, dos personas pueden encontrarse en las mismas condiciones empíricas y, sin embargo, tener razones diferentes para actuar. Además, las razones tienen un contenido y un carácter (es decir, pueden ser correctas o incorrectas), en cambio las explicaciones tienen sólo un contenido (son explicaciones sobre hechos del mundo) y carecen de pretensión normativa en sentido moral. Ciertamente, la ética no es el único cambio que contiene exigencias de normatividad, sino también la estética y el conocimiento (Korsgaard, 2000, 21). Pero también es cierto que la normatividad moral tiene una característica particular porque exige directamente no a nuestro juicio sino a nuestra voluntad y nos indica el si nuestras acciones son correctas o incorrectas. Un elemento adicional de las razones es que estas permiten articular un "campo normativo de justificación" (Forst, 2012, 18-23), que se configura como el espacio en el que las personas se dan razones mutuamente. El ejercicio del dar y recibir razones hace que las personas, ubicadas en contextos concretos, puedan establecer la distinción de lo correcto y lo incorrecto sobre la base de la fuerza de las mejores razones y de la libertad.

\section{KANT, Y LOS FENÓMENOS POLÍTICOS Y SOCIALES CONTEMPORÁNEOS}

El republicanismo kantiano se encuentra articulado por ese intercambio de razones respecto de lo correcto y lo incorrecto. Esto supone que las personas que dan y reciben razones son libres y no se encuentran inmersas en relaciones de dominación. Esto es así debido a que el republicanismo kantiano se encuentra articulado a través de una metafísica crítica (o de la libertad) que deja fuera el conocimiento de supuestos objetos metafísicos para abrir paso a ideas regulativas, en el plano de la razón práctica, articuladas en torno a la idea de libertad. De esta manera, el republicanismo kantiano articula con éxito el antidogmatismo que proviene de Hume y el combate a toda forma de dominación que proviene de Rousseau.

Ahora bien, los intentos de dominación pueden provenir de fuera de las personas y tratan de instalarse por la fuerza. En ese caso las personas podrían darse cuenta de ello y oponer resistencia. Pero también los esfuerzos de dominación pueden llevarse a cabo por medio de la instalación de discursos dogmáticos, impermeables a las razones, en la mente de las personas. Los discursos de los fundamentalismos religiosos, los que provienen del neoliberalismo o los que provienen de los populismos, tanto de izquierda como de derecha, son discursos dogmáticos que pueden capturar a las 
personas en el mismo seno de la sociedad civil.

Kant tenía mucha claridad respecto de que no es posible que la democracia republicana prospere si en la sociedad civil no se instauran relaciones de no dominación y las personas no se encuentran capturadas por discursos dogmáticos ${ }^{11}$. De hecho, la instauración de un Estado republicano, que incorpore la división entre los poderes ejecutivo, legislativo y judicial, no basta para garantizar la democratización de la sociedad. La experiencia de muchas democracias contemporáneas es que desde el interior de la sociedad están o han emergido discursos y proyectos que atacan la misma democracia republicana. En la escena contemporánea el populismo se ha convertido en una de las formas más peligrosas de dogmatismo que busca ahuecar las bases de la democracia representativa.

En un breve ensayo titulado De la superstición y el entusiasmo trata dos formas de perversión de la religión. Por un lado, la superstición surge de un espíritu debilitado, temeroso e inseguro, pues ha sido tomado por "la debilidad, el miedo, la melancolía junto con la ignorancia" (Hume, 2011 , 98) y las personas que anidan dicho carácter son presa fácil de la superstición, los ritos, las reglas y el sometimiento a un orden clerical. En cambio, el entusiasmo brota en espíritus "susceptibles de elevación y de presunción, procedentes de éxitos y sucesos favorables, de una salud exuberante, de la fortaleza de espíritu o de una disposición audaz y confiada (Hume, 2011, 98), de manera tal que no se encuentran dispuestos a obedecer a autoridades clericales y confían más en sus convicciones interiores que en alguna autoridad exterior. En ambos casos sucede que la autoridad que brota del razonamiento es desacreditada por favorecer ensoñaciones y creencias que provienen de la sumisión a una autoridad (como es el caso de tener creencias supersticiosas respecto de los poderes sobrehumanos de esta) o por el creer que la autoridad del sano juicio puede ser sobrepasada por la creencia que brota del entusiasmo que uno siente sobre sí mismo, debido al exceso de confianza que se tiene respecto de las convicciones interiores propias.

Estas formas de desacreditación de la autoridad del razonamiento y del sano juicio es lo que se encuentra, de manera secularizada, en el fenómeno del populismo, ya sea porque se tiene una sumisión al líder o se tiene una excesiva confianza en las convicciones interiores. En ambos casos se busca salir de los cauces regulares de la democracia constitucional y representativa. Las personas de espíritu supersticioso prefieren el seguimiento al líder populista que a las reglas de la democracia. La superstición, como señala Hume en su texto, se va adquiriendo paulatinamente, de modo que esas personas inseguras van entrando lentamente en el círculo de adoración al líder. Esto se pude ver con claridad en los fenómenos de los grupos fundamentalistas religiosos o en algunos movimientos políticos, como la adoración y sumisión absoluta a Hitler, o a Fujimori, o a líderes de izquierda. La lógica de la superstición se inserta en los grupos políticos y religiosos de carácter autoritario. El entusiasmo, por su parte, comienza como un gran estallido y termina por debilitarse y

11 Si bien Kant no tematiza el concepto de sociedad civil, hay lugares en su obra donde se refiere a ella, como en Respuesta a la pregunta ċqué es la Ilustración? Además, a través de la idea de comunidad ética desarrollado en La religión dentro de los límites de la mera razón, presenta herramientas para una teoría de la sociedad civil. 
disolverse con el tiempo. Ejemplos de ello son "los indignados" en España o el "Movimiento de los Chalecos Amarillos" en Francia. Estas manifestaciones, fruto del entusiasmo, están destinadas a disolverse, pues carecen de un proyecto organizado, pues las personas que los componen no comparten los mismos intereses y las mismas motivaciones. De estos movimientos es fácil vaticinar que terminarán desapareciendo o serán absorbidos por líderes autoritarios.

El populismo actual, tanto de derecha como de izquierda, sigue las pautas que Carl Schmitt presentó en los años 20 del siglo pasado. La estrategia de Schmitt consistió en arremeter contra la democracia representativa enfilando su armamento contra el Parlamento. Acusando al Parlamento de ser la combinación de los intereses particulares de los parlamentarios y de la corrupción, tanto Schmitt, por la extrema derecha, como los grupos de izquierda populista arremetieron contra el corazón de la República de Weimer. La sorpresa fue que los nazis, apoyados en las ideas de Schmitt terminaron por cargar con todo, y a través de una combinación de procedimientos previstos por la misma Constitución y artimañas duras terminaron por desmontar todo el Estado de Derecho Democrático.

Hoy en día, como entonces, los puntos de ataque son el Parlamento y la democracia representativa. Bajo la acusación de que el Parlamento está plagado de corrupción y de que los parlamentarios representan intereses particulares, especialmente empresariales, el grito "que se vayan todos" viene tanto de la derecha como de la izquierda. Bajo la idea de ampliar los márgenes de la democracia, ambos sectores movilizan a la población a través de discursos populistas. Ellos sostienen que el populismo representa la auténtica democracia. Pero el populismo es antidemocrático por esencia debido a que separa dos exigencias que deben ir siempre juntos, a saber, el de la libertad de elección y la del respeto a la autonomía de cada persona.

La estrategia populista consiste, tal como lo señala Ronald Reyes (Reyes, 2018), en afirmar que en la democracia la voz y el voto de cada persona tiene un peso, y que al momento de las decisiones se debe escuchar la voz de cada uno. Pero una vez hecho eso, y tomada la decisión por mayoría se cree que se está autorizado a vulnerar la autonomía de grupos minoritarios. Como bien advierte Reyes, el juego del populismo es escindir la libertad de elección de la autonomía. En esa escisión sucede que en nombre de la libertad de elección se va en contra de la autonomía y termina ejerciéndose la dominación de la mayoría contra la minoría.

Pero el discurso populista, de derecha o de izquierda, en sí mismo implica una forma de dominación debido a su dogmatismo. Líderes políticos de derecha o de izquierda infunden dicho dogmatismo, especialmente en momentos en los que la democracia representativa entra en crisis. Los seguidores altamente dogmatizados cierran sus sistemas de creencias y son incapaces de entrar en un intercambio de razones ni de evaluar qué razones cuentan con mayor justificación en el contexto concreto. Prisioneros de una descripción de los hechos que parece justificarlo todo, su capacidad de sopesar argumentos contrarios queda seriamente disminuida. De esta manera, la capacidad de ser crítico respecto de sus propias creencias ha sido completamente eliminada en nombre de una supuesta verdad absoluta que se presenta como la solución a todos los 
problemas políticos que aquejan a la sociedad mundial contemporánea.

\section{CONCLUSIÓN}

De lo presentado anteriormente podemos concluir que el escepticismo anti dogmático que proviene de Hume junto con la crítica a las relaciones de dominación que proviene del pensamiento de Rousseau han permitido a Kant articular una concepción sugerente de republicanismo. El filósofo alemán se encuentra inserto en una tradición de pensamiento político republicano. Pero el pensamiento republicano de Kant ha sido interpretado como partiendo del Estado y no desde la sociedad civil. Esto ha sido así porque en los trabajos de Kant existe una perspectiva del republicanismo desde el Estado y porque el filósofo alemán no desarrolló un concepto de sociedad civil. Sin embargo, como hemos visto, Kant también pensó en un republicanismo desde la sociedad civil y tenía claro que era importante que en ese ámbito se generaran relaciones republicanas entre las personas, a fin de hacer posible el mantenimiento del Estado republicano.

\section{REFERENCIAS BIBLIOGRÁFICAS}

Brandt, R. (1997). "Antwort auf Bernd Ludwig: Will die Natur unwiderstehlich die Republik". Kant-Studien, Vol. 88, pp. 218 228.

Forst, R. (2012). The Right to Justification. Elements of a Constructivism Theory of Justice. New York: Columbia University Press.

Forst, R. (2014). Justificación y crítica. Perspectivas de una teoría crítica de la política. Madrid: Katz.
Hume, D. (2003). Investigaciones sobre el conocimiento humano. Madrid: Alianza Editorial.

Hume, D. (2011). Ensayos morales políticos y literarios. Madrid: Trotta.

Kant, I. (1993). Teoría y práctica. Madrid: Tecnos.

Kant, I. (1999). Metafísica de las Costumbres. Madrid: Tecnos.

Kant, I. (2003). Sobre la paz perpetua. Madrid: Tecnos.

Kant, I. (2009). Crítica de la razón pura. México: FCE.

Kant, I. (2016). La Religión dentro de los límites de la mera Razón. Madrid: Alianza Editorial.

Korsgaard, C. (2000). Las fuentes de la normatividad. México: UNAM.

Niesen, P. (2001). "Volk-vonTeufeln-Republikanismus. Zur Frage nach den moralischen Ressourcen der liberalen Demokratie". Wingert, L. y K. Günther (eds.). Die Öffentlichkeit der Vernunft und die Vernunft der Öffentlichkeit. Frankfurt am Main: Suhrkamp, pp. 568-604.

Pettit, P. (1999). Republicanismo: una teoría sobre la libertad y el gobierno. Barcelona: Paidós.

Pettit, P. (2004). "Liberalismo y republicanismo". Ovejero, F., J. L. Martí y R. Gargarella (comps.). Nuevas ideas republicanas. Autogobierno y libertad. Barcelona: Paidós. 
Pettit, P. (2006). Una teoría de la libertad. Buenos Aires: Losada.

Reyes, R. (2018). Por qué el populismo

no es democrático. En: Revista IDEELE, $\mathrm{N}^{\circ} 279$.

Rousseau, J. (1996). Del contrato social. Discurso de las ciencias y las artes. Discurso sobre el origen y los fundamentos de la desigualdad entre los hombres. Madrid: Alianza Editorial.
Rousseau, J. (1998). Las confesiones. México: Conaculta.

Rousseau, J. (2008). El Emilio o de la educación. Madrid: Alianza Editorial.

Rousseau, J. (2015). Rousseau juez de Jean- Jacques. Valencia: Pre-Textos.

Scanlon, T. (2003). Lo que nos debemos unos a otros. ¿Qué signifca ser moral? Barcelona: Paidós.

Recepción: 08-06-19 Aceptación: 07-08-19 